The Canadian Journal of Higher Education La revue canadienne d'enseignement supérieur

Volume XXXIII, No. 3, 2003 pages 47-70

\title{
A Journey Toward Learner-Centered Curriculum
}

\section{CLAUDIA EMES \& MARTHA CLEVELAND-INNES}

The University of Calgary \& Athabaska University

\section{ABSTRACT}

In higher education, competing demands for accountability and innovation in the face of globalization, technology, and budget cuts cause us to consider how best to prepare learners who will learn for a lifetime. We contend that a shift in our understanding of curriculum design to accommodate learner-centeredness will provide the framework for preparing graduates for a lifetime of learning. Learner-centered curriculum proposes to create highly developed individuals, providing them the skills to continue creating learning experiences, digest current knowledge, and create new knowledge within the curriculum itself. Curriculum characteristics, as identified in the curriculum design project presented here, include content appropriate to the characteristics of a new society. It also includes all that is required of a curriculum in order for it to be transparent and easily understood as the scaffolding of learning. This definition of a learner-centered curriculum includes components that educators deem to be relevant and vital for students. It adds curriculum processes and required outcomes to prepare students for curriculum creation alongside educators. 


\section{RÉSUMÉ}

Au niveau des études supérieures, les exigences pour la responsabilité et l'innovation face à la globalisation, la technologie, et aux coupures budgétaires nous poussent à considérer comment mieux former ceux qui apprendront tout au long de leur vie. Nous croyons qu'un changement de notre compréhension de la planification du curriculum, davantage centrée sur l'apprenant, fournira un encadrement pour préparer les diplômés pour une vie d'apprentissage. Ce type de curriculum tend à développer chez les individus des habilités qui leur permettront de continuer leurs expériences d'apprentissages, d'acquérir des connaissances et même d'améliorer le curriculum. Les caractéristiques du curriculum, définies dans le projet de planification présenté ici, prennent en considération les caractéristiques d'une nouvelle société. Elles incluent également tout ce qui est nécessaire pour qu'un curriculum soit transparent et facilement compris comme structure visant l'apprentissage. Cette définition de la planification du curriculum inclut des facteurs que les éducateurs trouveront utiles et vitaux pour les étudiants. Sont aussi présentés des processus de curriculum et des résultats attendus afin de préparer les étudiants à collaborer avec les éducateurs à la création d'un curriculum.

In the nineties, universities began facing unprecedented pressure to change, to be reinvented to better meet the demands of learners in our twenty-first century, highly technical, globalized society. We had become a consumer society and although the debate about students as consumers had not yet erupted in the hallways of the academy, we began adopting business practices from the corporate world as universities moved into full scale strategic planning. The purpose of the planning was, among other things, to make the institutions more competitive in the changing market of higher education. To be competitive, institutions sought ways to distinguish their university from others of similar size and offerings. The purpose was to attract certain types of consumers those that the institutional focus can best serve. 
Drivers for change were related to the knowledge era that requires new learning outcomes in higher education, including understanding of learning itself as a key outcome. Add to this decreased public funding and greater demand by society for accountability, and change became an imperative. Probably the most ubiquitous forces were, and continue to be, the impact of technology and globalization. Harkins (1998) focuses on these forces when he speaks to the effect of global information systems that include, "the emergence of "situational' personal cultures" (p. 74). This phenomenon can be attributed to individual, intentional traversing of national boundaries that creates global awareness and values at a personal level. It suggests that the impact of globalisation through technology has created a unique set of individual needs that is characterized by the need to operate with a global perspective. Within these contextual changes the learner can no longer be viewed as a consumer of information. She or he must be viewed as a developer of knowledge.

This article focuses on a new concept of curriculum that responds to the call for new ways of serving learners in undergraduate education. A learner-centered curriculum design is the key vehicle that can shift from traditional systems of delivery, to new ways of engaging in the learning enterprise. The analysis begins by setting a context in which the issue of learner-centered curriculum has evolved. It will proceed to discuss the conceptual understanding of learner-centered curriculum, and then explore a case of defining learner-centered curriculum at the institutional level. Finally it examines the impact of learner-centered curriculum on two key constituents, students and faculty.

\section{CONTEXT}

Curriculum is the central structure that frames what and how a student acquires skill and knowledge within their chosen program at institutions of higher learning. Restructuring to address the changing context requires changes to content, delivery, and duration for completion of degree requirements. In addition, the process of curriculum design must also come under scrutiny and demonstrate accountability while at the same time teach students about how learning is designed. The call of the 
Wingspread Group on Higher Education (W.G.H.E., 1993) that new curriculum is to build a nation of learners is taken seriously.

\section{Traditions of curriculum design}

Learner-centered curriculum is a concept that has evolved from epistemological perspectives of inquiry and knowledge. Traditionalists' epistemology or logical positivism views knowledge as an objective entity that exists "out there" external to, and independent of, the knower. The traditionalist perspective, the dominant mode of inquiry within the academy since the origins of our North American universities, dictates a certain kind of teaching (Haworth \& Conrad, 1990). The professor is a sage who imparts universal truths. Curriculum content exposes students to the time-honored truths of society. Curriculum design, therefore, is based on a generalist to specialist or pyramid approach to course or content configuration. It is presumed that a student must study the 'great works' before they can move on to more specialized areas of study.

Emerging epistemology (Haworth \& Conrad, 1990) suggests there is not one single objective truth but rather that knowledge is socially constructed and that this paradigm is gaining acceptance. The emerging knowledge perspective suggests that the traditional canon must be expanded to include a balanced view of multiple rather than a single knowledge perspective. In order to ensure a holistic undergraduate experience for students, emerging knowledge claims that interpretivist, feminist, critical theory, post-structuralism, and multicultural scholarship must be integrated into the curriculum. This perspective has been described in several ways including constructivism and 'inclusive curriculum.'

Positivism, on the other hand, has not disappeared. To a certain extent there has been a merging of the old and the new. Institutions have responded with curricular expansion (integration) to provide a greater diversity in the perspective of knowledge. Multi-disciplinary and interdisciplinary programs have grown in number and complexity and more stakeholders embrace the view that knowledge is a social construct.

Constructivist curriculum (Gagnon \& Collay, 2001) has emerged in response to a focus on learning over teaching and the building of knowledge; constructivism answers the call for greater student engage- 
ment. It also opens up opportunities for students to more fully participate in shaping their learning experiences and constructing their own knowledge structures.

\section{Social role theory}

The obligation to meet high standards on specific academic requirements leaves a constructivist view on the margins in higher education. But the possibility of a new role for the student doesn't go unnoticed. One can look to social role theory to clarify these possibilities and the function of roles in the learning environment. A central debate in sociological theory surrounds the desire to illuminate the relationship between individual action and collective, societal structures within which individuals must act. Drawing from Durkheim (as interpreted in Collins, 1985) it is accepted that collective affiliation shapes individual action in meaningful ways; without this point of reference the individual loses sense of what is meaningful. Mead (1934) highlights another explanation, suggesting that individual action is a response to the actions of others around them, rather than a reference to a collective standard or requirement. In both cases, action is mediated by those factors external to the individual; in both cases the possibility of a symbiotic relationship between collective structures and micro-interaction seems to go unnoticed. They perceive the relationship as unidirectional, each commencing from a different point of departure. However, Durkheim's macroperspective is open to the individual, and Mead's "actors" generalize previous interactions such that the collection of responses from others guides thinking, feeling and behaving.

This provides very rich ground in which to plant a seed for a learnercentered curriculum. A view of external social influences on individual action provides a perspective from which to interpret a 'learner-centered' curriculum that is embedded in a social system. Mead and Durkeim provide a sociological perspective that allows one to consider a response from the 'social' that integrates students more fully into the collective university setting. Drawing from Parsons and Platt (1973), the university may act as a legitimate agent of socialization under the "moral authority of institutions" (p. 167) and the socialization effect of interpersonal attachment that 
occurs as part of the university experience (Weidmann, 1989). In so doing, the sense of 'centeredness' comes from a sense of collective affiliation rather than a response to individual exceptions. An understanding of the complexity curriculum design and an interest in the development of a new perspective for curriculum design was shaped by experience.

\section{CONCEPTUAL UNDERSTANDINGS OF A LEARNER-CENTERED CURRICULUM}

The term learner-centered is not new but rather is traditionally associated with student learning (Ulmer, 1969). Although it is not defined in Dewey's work, there exists a clear link from learner-centeredness to the concept of learning through experience (Delaney, 1999) and Rogers (1969) later notion of student-centered learning. The notion of holistic learning in higher education refers to, but does focus on learner-centeredness (Baxter-Magolda, 2000). Until recently, concentration on the learner in higher education, by any name, has had a minor presence.

Learner-centered curriculum will allow students to participate more fully in the arrangement of their own learning experiences in such a way that two key objectives are realized. One, students will participate in the shaping of curriculum thereby addressing the imperatives of many contextual issues that include a new situational personal culture. Two, student involvement is arranged such that students engage in metalearning; providing them the opportunity to learn about design and construction of purposeful learning activities.

Existing definitions are based on practice and ways of teaching in the classroom and focus on the conditions under which learner-centeredness occurs. Early definitions from the literature emphasize learner control (Lytle, Belzer, Schultz \& Vannozzi, 1989) and learner needs as the central consideration of "the ways in which we schedule classes, choose materials, deliver instruction, and integrate technology" (Soifer, Young \& Irwin, 1989, p.68). At other times, the point of reference for learnercenteredness is that which is different from what has existed previously in education; a shift from traditional education to something that remedies all that is deemed to hinder learning will be learner-centered 
(Smith \& Kolosick, 1996). McCombs and Whistler (1997) present a definition of learner-centered which focuses on both the learner and learning:

The perspective that couples a focus on individual learners (their heredity, experiences, perspectives, backgrounds, talents, interests, capacities, and needs) with a focus on learning (the best available knowledge about learning and how it occurs and about teaching practices that are most effective in promoting the highest levels of motivation, learning, and achievement for all learners). This dual focus then informs and drives educational decision making. The learner-centered perspective is a reflection of the twelve learner-centered psychological principles in the programs, practices, policies, and people that support learning for all. (p. 47)

The psychological principles as approved by the American Psychological Association are organized in five domains that include basic factors that have been identified as having an impact on learning: meta-cognitive and cognitive, affective, developmental, personal and social, and individual differences (Stark \& Lattuca, 1997). This foundational knowledge should be part of what drives all instructional activity in the classroom. However, progressive thought in education suggests that this approach to learners is "only cognitive, that the students remain relatively inactive or even passive, that the idea that large groups of students could be offered the same content and would learn the same is an illusion" (Peters, 2000, p. 2). The practice of a learner-centered approach in teaching faces further debate.

Parallel concerns are emerging in reference to curriculum. Traditionalists feel that the move toward a more inclusive curriculum has lead to a decline in the quality of programs within universities, while progressivists welcome such a move (Nemec, 1997). Within the academy the demand to hear the voice of learners comes from several sources including the senates and boardrooms, but Graff (1992) contends that the undergraduate student voice has been essentially ignored in the debate over curriculum reform.

With the exception of continuing and adult education there are few, if any examples of learner-centered curriculum (Pina, 1994; Guenin-Lelle, 
1991, Nunan, 1988) in higher education. More information is available about learner-centered teaching practice in postsecondary (Gunawardena, 1992; O'Banion, 1997; Reese, T., 1994; Reynolds \& Wener, 1994). Agreement on what it means will do much to shift toward learner-centered curriculum.

\section{Defining learner-centered curriculum}

The term learner refers to the role that is played by the constituency of students in a program: learners as a collective group, and as a term that refers to each individual's unique attributes as they play this role of learner. A learner-centered curriculum addresses both definitions of learner. The term "centered" refers to the idea that the learner will be a continuous point of reference, but not the only point of reference.

Implied in the implementation of a learner-centered curriculum is that it facilitates learning about curricular decision making processes, infused in both program decisions and course relevant decisions. Learners play an active participatory, knowledgeable role; participation includes knowledge development in the area of learning and curriculum design. In a learner-centered curriculum students will be afforded opportunities for making informed curriculum decisions. The faculty role will be adjusted to accommodate the new role of the student. The definition of a learner-centered curriculum must include a set of learning experiences that will allow students to participate more fully in the arrangement of their own learning experiences.

\section{LEARNER-CENTERED CURRICULUM: A CASE AT THE INSTITUTIONAL LEVEL}

In the mid-1990s, institutional planning at the University of Calgary recognized the impetus for change in undergraduate education, and the dramatic force at which it was developing. Not only were the contextual changes numerous, many had a large impact on their own. Shifting student characteristics, increased competition, rapid globalization, changes in funding sources and amounts for teaching and research, increased calls for accountability and the expanse of information and communication 
technologies added to an undeniable requirement to reconsider the way education programs are designed and employed.

Within a young university accustomed to creating curriculum that is discipline-specific, with only one universal standard, a minimum of 20 full course equivalents for a four-year bachelor's degree, this was the first attempt to create a dialogue around the concept of an institutionallevel curriculum change. It was the team's responsibility to create a new design that would receive institutional approval.

In the first phase, a situation assessment, an extensive review of the theoretical underpinning of the curriculum design synthesized with the current curricular situation produced a solid foundation upon which a new curriculum could be built. A continuous process of research, critiquing, discussing, debating and analyzing curriculum, characterized the scholarly approach.

\section{THEORETICAL INFLUENCES}

Key to the shaping of the new curriculum was the work of Schwab (1966), Kolb (1984) and de Nicolas (1989). While Schwab looks at patterns of relationships among central elements of curriculum design, de Nicolas reminds us of the central outcome of university education, developing habits of mind, ways in which students carefully and skillfully perceive and organize information as it is presented to them. de Nicolas wants a broadly based understanding about information and what counts as knowledge. Whereas Schwab takes the subject matter as a point of departure, de Nicolas is interested in the broadest outcomes. Schwab shapes the ways we think about the teaching-learning transaction while de Nicolas is intent on building a solid foundation for critical thinking and a plurality of habits of mind.

Kolb's (1984) description of a learning cycle was added to the mix of conceptualization. Two central themes underlie Kolb's learning cycle: (1) in the education setting learning must be considered as a process, not strictly as an outcome, and (2) this process should be seen as continuous in nature and grounded in experience. Four structural dimensions shape this process of learning: concrete experience, reflective observation, 
abstract conceptualization and active experimentation. Schwab's (1966) analysis prompted the team to view the structural relationships in the learning environment such as noting the relationship between the student and the instructor. Kolb further suggested the scope of activities that a student should engage in while developing the habits of mind that are suggested by de Nicolas (1989). By this direction, understanding 'learning as a process' is identified as part of 'learning outcomes,' or the results of this process, in a learner centered curriculum. This often-obscured nuance about learning should be explicit in the foundations of curriculum.

\section{ASSESSMENT}

While the team was assimilating a theoretical foundation, it was also conducting internal research on the existing programs at the university. The University of Calgary is a research institution that services over 20 , 000 undergraduate students with 110 programs in 16 Faculties. An institutional program audit revealed detailed information regarding student flow through faculties, complexities in program requirements, and the demand on certain courses, both in terms of student enrolment and program requirements. It further highlighted the issues that often bring curriculum change to a halt; lack of common understanding of program requirements, workload, entanglement problems, service issues, and capacity problems can sideline curriculum discussion

The audit also found that curriculum was designed as a suite of program specific courses and drawing on more than the host department. Standard learning was lecture-dependent and instructor-centred, with examinations conducted on a course-by-course basis. Learning enhancement includes laboratories, field schools, practica, clinical placement and study abroad. However unique curricular innovation was underway in pockets across the campus; these ideas were captured and integrated where possible.

\section{Laying the foundation for change}

Through documentation and conversation the theoretical foundation and the current realities were synthesized, resulting in a series of 
suggestions and ideas for curriculum reform. They were continually shaped and revised through conversations among team members and the rest of campus. Early iterations of a new model opened the door for a campus-wide debate about curriculum and provided a platform for creativity in design. Several models that represented possible directions for change preceded the final product. For various reasons, particularly their uni-dimensional character, these models had to be rejected. The scope of the new model had to be sufficient to encompass the synthesis of theory and reality, thus it became obvious that only a complex, multidimensional template would be suitable for undergraduate curriculum in a large, multi-disciplined, research-intensive university. Established learner-centered principles, the foundation of the new curriculum, is founded in three well developed areas: core competences, profile of the graduates, and common curricular features.

\section{Core competencies}

Critical to the new curriculum model is how well it aligned with the University's recently developed strategic direction as well as reflecting an existing statement of core competences that was approved for adoption as overarching skill requisites for all programs. Core competencies are the skills and abilities acquired during postsecondary education that genuinely enable individuals to think, analyze, and communicate. Fostered in academic disciplines, they transcend subject-specific knowledge and are widely applicable. Core competencies, deemed an essential foundation for lifelong learning, and the intellectual abilities that contribute to the individual's moral and spiritual development and that encourage leadership, responsibility and respect for the presence of human values were identified. These include:

- Critical and creative thinking

- Analysis of problems

- Effective oral and written communication

- Gathering and organizing information

- Logical calculation, mathematical ability

- Abstract reasoning and its applications 
- Insight and intuition in generating knowledge

- Interpretative and assessment skills

\section{Profile of graduates}

To give the design work a central point of reference, such as a profile of a signature student or an 'ideal type' (Neuman, 1996), the Undergraduate Curriculum Redesign Team (UCRT) looked to the desired end of curriculum work, the graduating student. They then created a comprehensive description captured in the following statement: Graduates of the University of Calgary are intellectually powerful; they can:

- Pose questions which approach the frontiers of knowledge

- Solve the academic, professional, and ethical problems they face

- Relate theory and practice

- Work alone and with others

- Communicate meaning in competent and effective ways

- Engage meaningfully with those from other cultural and linguistic communities

- Understand the world from a variety of perspectives

\section{Common curriculula features}

This was an institution-wide plan for curriculum created within the context of a framework that would accommodate each undergraduate program on campus. It was anticipated that alignment with this new template would occur via planning and development at the departmental level. The central purpose was to guide the redesign and creation of undergraduate curricula at the program level, without compromising the requirements of a field of study or accreditation standards.

After two years of constant interaction with the academic community through presentations, discussion group, and redesign team meetings, the following seven curriculum framework features were adopted:

A clearly identifiable field of study. All degree programs at the University of Calgary will allow students to develop extended competence in at least one field of study. A field of study may be disciplinary, 
in that it is defined both by the phenomena it examines or interprets and by the methods it uses. It may be interdisciplinary and defined primarily by its scope and its use of different methodologies drawn from a variety of disciplines. It may be professional, and thus defined primarily by the demands of accreditation requirements or it may be creative, and in this case defined primarily by a creative domain. Physics, for example, is a disciplinary field whose scope is the physical world and whose methods include experiment and mathematical modeling. Women's Studies is an interdisciplinary field which focuses on women's history and place in contemporary society and which uses different methodologies drawn from a variety of disciplines as well as interdisciplinary methods developed for the field. Nursing is a professional field defined by the demands of the nursing profession, while dance is a creative field with a performance context.

A defined interdisciplinary component. Interdisciplinarity is the purposeful integration and synthesis of knowledge, skills and methodologies from different fields of study and different perspectives. Interdisciplinarity can blend and work outside of disciplinary lines in the creation of new ways of knowing. Students with significant exposure to different methodologies and fields of study are more likely to be able to solve problems, to answer complex questions, to address broad issues, and to achieve some measure of unity of knowledge (Klein, 1990).

An international component. Providing students with an understanding of international relationships and issues is the primary goal of an international component. It will offer a particular view of the benefits and challenges of interaction of peoples, cultures and environments around the globe. It serves to develop an awareness of international, multicultural or aboriginal perspectives. In order to contribute to the world in which they will live, students require an awareness and understanding of the increasing connections between people. Encouraging a meaningful interface with people, their cultural artifacts and modes of expression outside one's own cultural identity helps to realize this awareness. In addition, the international component of the curriculum will encompass a global perspective that expands the scope of any endeavor to include an understanding of world issues. 
An experiential learning component relevant to program objectives. Experiential learning refers to parts of programs that engage students in active, practical learning within and beyond the normal instructional setting. While the term 'experience' in common usage could be applied to any aspect of learning, 'experiential learning' refers to comprehensive engagement of the learner. It can lead to broader, more enduring learning outcomes (Kolb, 1984). The relevance of content can be assessed and placed into context through reflective observation. This practice and reflection should be an integral component of a student's academic program, substantially related to his or her scholarly pursuits. Experiential learning activities are often open-ended in the sense that neither the student nor the instructor has prior knowledge of all the results.

Provision for broad and extended faculty-student interaction at the program level. For the purposes of curriculum redesign, broad and extended faculty student interaction is the process of consistent and frequent formal and informal exchanges that focus upon learning in a manner appropriate to the program. This will allow relationships between faculty and students to develop in a way that fosters mutual respect, acceptance of diversity and an understanding of differences in teaching and learning styles. This allows the student perspective to be considered during the design of the learning environment. In most programs, increased faculty student interaction will evolve naturally from the implementation of other key curriculum features, such as experiential learning and integration of research. It is expected that this interaction will deepen student engagement in learning.

Integration of research. The purpose of doing research is to create and validate knowledge in a central field of study. As a major research institution it is essential to focus on research activities as an enhancement to teaching. Curriculum designed to integrate research gives students the opportunity to learn about, participate in, and report upon current research and/or conduct a research project of their own choice. This component offers students an understanding of research methodologies and a way to critically evaluate results of research.

Explicit syllabus. The explicit syllabus offers the students a view of a degree program in its entirety. It specifies the purposes and objectives 
of the program, how these are achieved and tested, what the result will be for students in terms of their capabilities upon graduation. The explicit syllabus should be formulated to optimize the variety of ways faculty members can teach and students can learn. The explicit syllabus will be available to students before they begin their studies to assist them in choosing a program appropriate to their interests and career aspirations, and will serve as a guide to the program as they progress through it. Students will have more awareness of the purpose of the instruction they receive, and presumably be better prepared and better motivated to participate in educational experiences. Instructors will also have a clearer idea of how the content and skill development in any individual course fits into a student's whole program. The syllabus will also be a useful reference, a multipurpose guide to program design, content, and an invaluable tool for program assessment.

The framework was presented, debated and passed by the General Faculty Council. Thirteen pilot programs served as examples of implementation of the new features. A structure for seconding curriculum redesign champions, department by department was a critical step in implementation. Named 'curriculum fellows,' a stipend for teaching release or research funding was provided to faculty members from undergraduate programs willing to work on program redesign. Working in a cross campus consultation, 80 undergraduate programs were redesigned over a two-year period.

\section{IMPACT ON STUDENTS AND FACULTY}

Curriculum redesign included changes toward a more unified focus on the experiences of the learners. The following priorities set the stage for the development of a curriculum template for all programs. First, opportunities for students to synthesize information across courses and disciplines were required. Second, delivery methods that required active, meaningful engagement had to be identified and integrated. Third, the more nebulous conditions of learner-centeredness, curricular best practices, and attention to the broad needs of students had to be met. 
Students were engaged in the creation of the new template, and in creating implementation strategies in individual programs. Although a step in the right direction, the new template and its procedures did not go far enough in creating a learner-centered curriculum.

During the redesign process, the roles of the professor and the learner in this new model of curriculum came under question, particularly in terms of delivery within the new framework and responsibilities for curriculum decision. How should decisions be made and who should be responsible and at what juncture within a program? It became increasingly clear that students should learn more about curriculum design and consequently play a larger role in the design of their individual programs.

\section{Role adjustment.}

One reason that the curricular redesign doesn't imbed is because there is a lack of support and momentum to effect new roles required of students and faculty in a significant curriculum revision. In a shift to learner-centered curriculum, students should have greater latitude in the choice of evaluation procedure, how the content is acquired, and deadlines for fulfilling requirements.

Students. Prior to curriculum redesign, students played a very traditional role on campus. Program choice was made up of required courses, bounded and open options, requirements regarding breadth and limitations about how much of one subject area could be covered. Individual instructors determined choices within each course. No campus-wide agreements on teaching methods, learning experiences or assessment techniques were in place. The extent of learner-centeredness was determined by the knowledge and skill of faculty members.

Learner-centered curriculum will allow students to participate more fully in the arrangement of their own learning experiences, such that they can continue to do so for a life-time. This is a role adjustment for students that will require a complementary role adjustment in expectations of faculty.

The role of student is institutionalized, that is, it is part of every formal education experience and carries with it a set of obligations and 
privileges students learn through the process of socialization: learning the appropriate behaviors. Students take on individualized roles as learners, even when they are not taught as individuals. This role is constructed for them and by them over time as a synthesis of experience, influence and biology: learning style, temperament, cognitive endowment, etc.

Gardner (1999) describes the tension between student expectations and those of the universities. "Today's students have a heightened sense of their own independence that is at odds with the institution's sense of its own authority" ( p. 23). He attributes professors with all the authority for curricular decisions: required courses, pedagogy, standards, and evaluations. Furthermore, there is no evidence that universities have systematically taken into account student preferences for learning

We contend that current structures place students in a subordinate role and that the shift from subordinate to the role of a participant in a shared journey of learning is the benchmark of learner-centeredness. The student will be part of the co-creation of the learning experience. What will this look like? Consider the common places of learning by focusing on the faculty member, the content and the student. Currently faculty, as content experts, select disciplinary content, align it with universal or corequirements and sequence it over four years within a program. In addition, they set standards and design procedures to determine students' knowledge outcomes. Evidence of learner-centered curriculum is found in the extent to which students are free to participate.

Faculty. Along with the new role for the learner comes a new role for the professor. In our vision, faculty will continue to set boundaries but students will be supported individually in greater participation in curriculum design through opportunities to express themselves while fulfilling their shared responsibility in the design and delivery of curriculum. For example, faculty set boundaries around the sequence in which courses will be delivered, the knowledge outcomes, and the standards of assessment. In order to make these decisions the learner needs detailed information, delivered in a timely fashion about the program and its courses. Therefore, an explicit program syllabus is required that provides in advance all the detail about a program. It clearly describes not just the content with goals and objectives but the questions to be answered, the 
various learning experiences in the form of readings, exercises, human interactions, and assignments. All are laid out in advance but incorporate choices for the student. In general terms most students assume a role as receiver and passive learner. The new role of the learner will be multidimensional. The repertoire will include the ability to move from passive to active and from receiver to producer as needed.

Add to the instructional requirement the addition of teaching learners about learning in support of more independent self-managed learners, materials, schedules, activities and assignments, and more fluidity and flexibility is required. The role moves from what could be called ' tour guide', the interpreter of content, to 'excavation supervisor', where the job becomes one of responsibility for handing out maps, tools, and identifying potentially important places to dig. 'Finds' are returned to the excavation boss for certification and verification. Fostering independence goes from wishful thinking to a deliberate education outcome. Ege, Coppola, \& Lawton (1996) described a new relationship between professor and students wherein the professor moves from a role of authority to that of coach and mentor - "the expert learner" who guides the processes by which the student learns about subject matter and most importantly learns about learning.

\section{CONCLUSION}

According to Freedman (1998), there are five main issues to be considered in the design of good curriculum. First the epistemological issues which consider the ways in which knowledge is conceptualized in relation to formal education. Next are the information issues that are addressed in the representation of knowledge in the curriculum, and then the developmental issues, which are concerned about the developmental level of the student. The final two issues are the outcome issues in relation to curriculum goals and objectives, and finally the structural issues. The latter refers to the ways in which knowledge is organized and implemented in the curriculum as well as how knowledge is represented through information constitute the issues of structure. 
A learn-centered approach does not ignore these issues. On the contrary it is the inherent response to these issues that distinguishes learnercenteredness from other approaches. In a learner-centered curriculum the conceptualization of knowledge in relation to formal education moves beyond positivism and constructivism to a new roles for students and professors that allow for discovery and creation of knowledge that is more satisfying for the learners. While social construction ignores the importance of learning how to manage the development and delivery of curriculum, the learner-centered approach focuses on this as a key outcome.

Information issues concern the representation of knowledge in cur-. riculum, which in turn emerges through various educational experiences. It is the production of these forms of representation that changes knowledge into information in different ways (Freedman, 1998). A learnercentered curriculum utilizes various educational experiences but the student becomes a participant in the decision-making process of designing and selecting educational experiences. In the process this approach also recognizes the developmental level of students. The role of the learner is determined in terms of their academic capacity and not according to the traditional assumptions regarding undergraduate, masters or doctoral level. This leaves the door open to the possibility of crossing boundaries of traditional structures of curriculum. It suggests that our traditional understanding of what and how things should be studied at certain levels will be challenged in a learner-centered curriculum. At the same time, as an active participant in the process they are more likely to understand and accept the structural formats that have been established based on sound pedagogical theory.

The knowledge era requires new learning outcomes in higher education including understanding of learning itself as a key outcome. Responding to "the needs of an information- and technology-based global economy, the complexities of modern life, the accelerated pace of change and the growing demands for competent, high-skill performance in the workplace require ( $\mathrm{sic}$ ) that we produce much higher numbers of individuals--whether high school, community college or four-year graduates--prepared to learn their way through life" (WGHE, 1993). 
Approval of the framework and the redesigned programs was relatively straightforward. Indeed over 80 programs were approved with minor interruptions and/or adjustment to the departmental proposals. Unfortunately it appears that the implementation stage that followed the approval stage did not create a dramatic shift to a fuller student participation in the curriculum design process. In retrospect there are several areas where we can look to find explanations for the less than remarkable change in the way students engage in designing curriculum.

The realization of learner-centered curriculum challenges universities to reconsider many of the traditions that have governed delivery of programs in higher education. For example, many students still face unusual difficulties in transferring credits. For others a variety of options may exist for acquiring credits, however universities restrict where, when and how students take courses. These two issues alone can provide the basis for next steps. Students must be asked how best to resolve these issues. It is one way to engage them in thinking about their curriculum and it forces them to think about the most effective way to get the education that best suits them.

Changes in economic and social structures demand adjustments in the process and outcomes of education. Our definition of learner-centered curriculum responds to the requirements as they are currently envisioned in a globalized, highly technical information based society. The proposed outcome of engaging in a learner-centered curriculum is highly developed individuals with the skills to continue the process of creating learning experiences, digesting current knowledge, and creating new knowledge within the curriculum itself. Curriculum characteristics, as identified in the curriculum design project presented here, include content appropriate to the characteristic of a new society. It also includes all that is required of a curriculum in order for it to be transparent and easily understood as the framework of learning. In this way, the revised definition of a learnercentered curriculum includes components that educators deem to be relevant and vital for students. It adds curriculum processes and required outcomes to prepare students to create curriculum with educators. 


\section{References}

Barr, B. \& Tagg, J. (1995). From teaching to learning: A new paradigm for undergraduate education. Change, 27(6), 12-25.

Baxter-Magolda, M.B. (2000). Teaching to promote holistic learning and development. New Directions for Teaching and Learning, 82, 88-98.

Collins, R. (1985). Three sociological traditions: Selected readings. New York, NY: Oxford University Press.

Delaney, J.G. (1999). What are learner-centered schools? Atlantic Provinces Education Foundation Summer Leadership Institute. Retrieved August 1,2001 from http://www.stemnet.nf.ca/apefinstit99/article.html

de Nicolas, A. (1989). Habits of mind: An introduction to the philosophy of education. New York, NY: Paragon, House.

Ege, S.N., Coppola, B.P., \& Lawton, R.G. (1996). The University of Michigan undergraduate chemistry curriculum: 1. Philosophy, curriculum and the nature of change. Journal of Chemical Education, 74 (1 \& 2), 74-91.

Freedman, K. (1998). Culture in curriculum. In J.A. Mestenhauser \& B.J. Ellingboe (Eds.), Reforming the higher education curriculum: Internationalizing the campus. Phoenix, AZ: The American Council on Education and the Oryx Press.

Gagnon, G.W., \& Collay, M. (2001). Designing for learning: Six elements in constructivist classrooms. Thousand Oaks, CA: Corwin Press.

Gardner, D.P. (1999). Meeting the challenges of the new millennium: The university's role. In W.Z. Hirsch \& L.E. Weber (Eds.), Challenges facing higher education at the millennium. Phoenix: AZ: The American Council on Education and The Oryx Press.

Graff, G. (1992). Beyond the culture wars: How teaching the conflicts can revitalize American education. New York, NY: W.W. Norton.

Guenin-Lelle, D. (1991, Oct.). On organizing a learner-centered advanced conversation course. Paper presented at the conference on Bridging Theory and Practice in the Foreign Language Classroom, Baltimore, MD.

Gunawardena, C. (1992). Changing faculty-roles for audiographics and online teaching. American Journal of Distance Education, 6, 58-71.

Harkins, A.M. (1998). Global academies as global self-organizing "think tanks". In J.A. Mestenhauser, \& B.J. Ellingboe (Eds.), Reforming the higher education curriculum: Internationalizing the campus. Phoenix, AZ: The American Council on Education and the Oryx Press. 
Haworth J.G., \& Conrad, C.F. (1990). Curricular transformations: Traditional and emerging voices in the academy. In C.F. Conrad \& J.G. Haworth (Eds.), Curriculum in transition: Perspectives on the undergraduate experience. ASHE Reader Series: Ginn Press.

Kolb, D.A. (1984). Experiential learning. Englewood Cliffs, NJ: Prentice Hall.

Klein, J.T. (1990). Interdisciplinarity: history, theory and practice. Detroit, MI: Wayne State University Press.

Lytle, S.L., Belzer, A., Schultz, K., \& Vannozzi, M. (1989). Learnercentered literacy assessment: An evolving process. New Directions for Continuing Education, 42, 53-64.

McCombs, B.L., \& Whistler, J. S. (1997). The learner-centered classroom and school: Strategies for increasing student motivation and achievement. Jossey-Bass Education Series. San Fransico, CA: Jossey-Bass.

Mead, G.H. (1934). Thought as internalized conversation. In R. Collins, (Ed.), Three sociological traditions: Selected readings. New York, NY: Oxford University Press.

Nemec, M.R. (1997). The role of curricular debate in the university. The Review of Higher Education 20(2), 215-227.

Neuman, W.L. (1996). Social research methods. Toronto, ON: Allyn and Bacon.

Nunan, D. (1988). Principles for designing language teaching materials. Guidelines: A Periodical for Classroom Language Teachers, 10(2), 1-24.

O'Banion, T. (1997). Creating more learning centered community colleges. Newport Beach, CA: League for Innovation in Community Colleges

Parsons, T., \& Platt, G.M. (1973).The American university. Cambridge MA: Harvard University Press.

Peters, O. (2000). Digital learning environments: New possibilities and opportunities. International Review of Research in Open and Distance Learning, 1, 1-19.

Pina, A. (1994). Macro I.S.D.: Using an instructional design paradigm to plan non-traditional degree programs. (ERIC Document Reproduction Serial No: ED368341).

Rogers, C.R. (1969). Freedom to learn. Columbus, OH: Charles E. Merrill Publishing Company.

Reese, T. (1994). Adult learning research and effective college teaching: Perceptions and Practice. Paper presented at the Association for the Study of Higher Education meeting, Tucson, AZ. 
Reynolds J., \& Wener, S.C. (1994). An alternative paradigm for college reading and study skills courses. Journal of Reading, 37(4), 272-278.

Schwab, J. (1966). The teaching of science as enquiry elements. In P.F. Brandwein (Ed.), A strategy for teaching science in the elementary school. Cambridge, MA: Harvard University Press.

Smith, K., \& Kolosick, T. (1996). The shift to a learner-centered university: New roles for faculty, students and technology. Proceedings of the Association of Small Computer Users in Education Summer Conference, North Myrtle Beach, SC.

Soifer, R., Young, D., \& Irwin M. (1989). The academy: A learnercentered workplace literacy program. New Directions in Continuing Education, $42,65-68$.

Stark, J.S., \& Lattuca, L.R. (1997). Shaping the college curriculum: Academic plans in action. Toronto, ON: Allyn and Bacon.

Ulmer, E.J. (1969). Instructional development in higher education: Basic premises of a learner-centered approach. Education Technology, 9(4), 10-16.

Weidmann, J.C. (1989). Undergraduate socialization: A conceptual approach. In J. Smart (Ed.), Higher education: Handbook of theory and research (pp. 289-322). New York, NY: Agathon.

Wingspread Group on Higher Education (WGHE). (1993). An American Imperative: Higher expectations for higher education. Retrieved August 14, 2001 from http://www.pbs.org/als/revolution/whatis/wingspread.htm 